DOI: 10.12731/2227-930X-2019-3-50-56

УДК 004.624

\title{
ПРОЕКТИРОВАНИЕ ИНФОРМАЦИОННОЙ СИСТЕМЫ УПРАВЛЕНИЯ ЭНЕРГОРЕСУРСАМИ В СФЕРЕ ЖИЛИЩНОГО ХОЗЯЙСТВА
}

\section{Лысанов Д.М., Еремина И.И., Иимурадова И.И.}

В статье рассматриваются вопросы, связанные с совершенствованием сферы жилищно-коммунального хозяйства: разработка регулирующих, управляющих конфигуращий оборудования, изменение параметров работь в режиме реального времени, дистаничионый сбор данных с приборов учета, регулировка объемов предоставленных коммунальных услуг. Все это позволит улучшить мониторинг функционирования системы сбора данных о полученных коммунальных услугах и повысить оперативность выявления энергетических потерь в системе.

Ключевые слова: информационная система; управление; жилищзное хозяйство.

\section{DESIGN OF ENERGY MANAGEMENT INFORMATION SYSTEM IN HOUSING SECTOR}

\section{Lysanov D.M., Eremina I.I., Ishmuradova I.I.}

The article deals with issues related to improvement of the sphere of housing and communal services: development of regulatory, control configurations of equipment, change of parameters of operation in real time, remote collection of data from metering devices, adjustment of the volume of provided communal services. All this will improve monitoring of the system of data collection on received utilities and increase the speed of detection of energy losses in the system.

Keywords: information system; management; housing. 


\section{Введение}

Сегодня проблема энергосбережения - одна из основных задач, влияющая на практически все социально-экономические процессы развития человеческого общества. Большие возможности сохранения энергии находятся в системах водоснабжения и теплоснабжения зданий, так как на выработку тепла расходуются до 40\% добываемого топлива.

Особенности жилищно-коммунальной сферы определяют специфические характеристики ее функционирования. Наличие монополизма в жилищной сфере; высокая социальная ответственность; ограниченный характер предоставления и потребления услуг; высокий уровень комплексности оказания услуг в рассматриваемой сфере, что отражается в постоянном взаимодействии жилищных организаций со всеми предприятиями - поставщиками различных энергоресурсов - это наиболее значимые и специфичные особенности функционирования жилищной сферы, которые нужно обязательно учитывать для повышения эффективности управления.

\section{Материалы и методы исследования}

Для автоматизации учета потребления энергоресурсов потребуется установка импульсных счетчиков, принцип работы которых похож на работу обычных механических счетчиков: вода вращает крыльчатку, рассчитываются ее обороты и отображаются на циферблате. Один оборот стрелки соответствует определенному объему израсходованной воды и равен $0,01 \mathrm{~m}^{3}$ или 10 л. К концу стрелки прикрепляется магнит, когда стрелка выполняет целый оборот, при взаимодействии с магнитом создается импульс, который передается в вычислитель или счетчик. После этого зарегистрированный импульс может передаваться через интернет по любым доступным каналам связи в систему учета потребления энергоносителей.

Система монтажа таких счетчиков следующая: сначала устанавливается система аварийного перекрытия воды, которая отключает воду автоматически, что позволит ограничивать подачу воды должникам. Для управления присоединяется контролер на базе 
аккумуляторной батареи, в имеющийся разъем подключается радиостанция, импульсные счетчики подсоединяются к отдельному хранилищу данных, подключается GSM-модуль для передачи собранных данных со счетчиков воды и электроэнергии.

Автоматизированный съем данных осуществляется без доступа в квартиру. В получаемых из квартиры данных указываются объемы потребления и возможные неисправности оборудования. Такая схема работы снизит нераспределенные объемы воды, что поможет сэкономить денежные средства, повысит качество предоставляемых услуг, также позволит исключить чрезмерный расход и снизит плату за жилищные услуги, работа с должниками станет проще.

Если произойдет вмешательство в работу счетчика, данные будут отражаться при сборе информации. За вмешательство в работу счетчика к собственнику будут применены взыскательные меры, а при выходе из строя прибора учета ему необходимо будет полностью возместить стоимость оборудования.

\section{Результаты исследования}

Система сбора, анализа и управления данными включает следующие основные компоненты (рисунок 1) [1]:

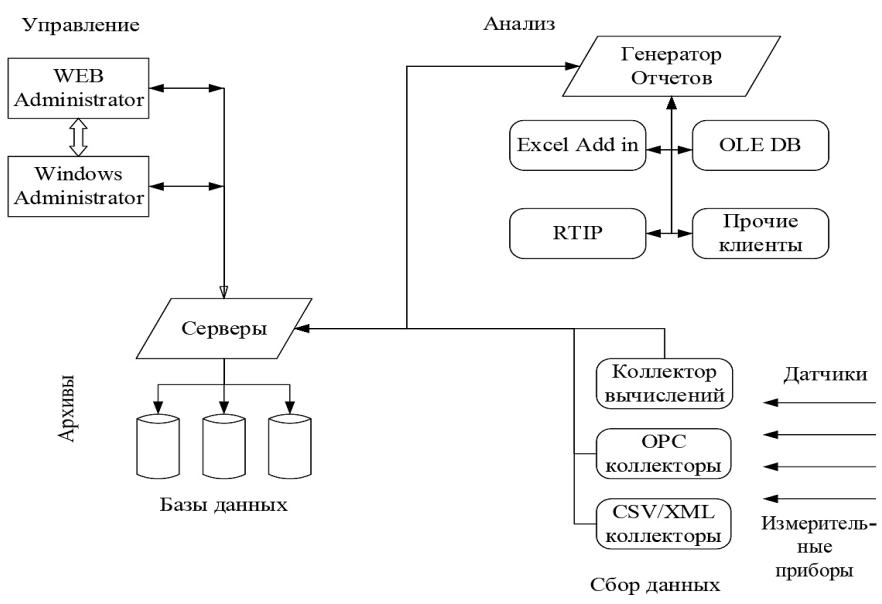

Рис. 1. Схема системы управления данными 
RTIP - интерактивный процессор периферийного терминала. Помогает собирать данные с разных приборов и формировать общую отчетность.

Excel - данные программы Excel. Таблицы, вычисления, диаграммы, созданная ранее структура учета и расчета.

OLE DB - технология, позволяющая приложениям унифицировано работать с данными из разных источников и хранилищ информации, отделяет хранилище данных от приложения.

ОРС коллекторы - программа накопления и форматирования данных для программы управления и дальнейшего ее анализа.

$\mathrm{CSV} / \mathrm{XML}$ - формат XML представляет собой набор правил для кодирования документов в машинный формат. CSV представляет собой файловый формат для хранения табличных данных в виде простого текста.

Коллектор вычислений - накапливает числовые показатели и формирует из них необходимую отчетность.

\section{Обсуждение}

Можно использовать несколько различных конфигураций систем управления данными [2]:

1. Система организована и настроена на обычном компьютере. Тогда на контроллере находятся сервер данных и веб-сервер, а на компьютере - веб-браузер. Для отображения информации необязательно применять компьютер, можно использовать любое устройство, на котором запускается веб-браузер и имеется доступ к контроллеру по сети.

2. Основой системы является сервер данных, который остается в контроллере, веб-сервер располагается на компьютере или в облаке. Его роль может выполнять персональный компьютер, а система отображения с веб-браузером устанавливается на любом другом компьютере, планшете или смартфоне.

3. Веб-сервер и сервер данных находятся на одном компьютере или облачном сервере, что позволяет создать систему управ- 
ления не только для нескольких локальных контроллеров, но и для контроллеров, расположенных на значительном расстоянии друг от друга.

\section{Заключение}

Установка и использование предлагаемой системы имеют следующие особенности:

1) На этапе внедрения требуются значительные затраты, особенно для старого жилого фонда. Внедрение такой системы управления актуально для новостроек, так как стоимость установки системы будет входить в стоимость квартиры.

2) Не требуется никаких договоренностей с жильцами на снятие данных с приборов учета - все необходимые данные можно выгрузить через специальную программу, что повышает достоверность данных приборов учета.

3) Работа с должниками по оплате становится более простой - отправляется предписание по почте, совершается звонок по телефону. Если никакой реакции не последовало, необходимые документы передаются в суд. Если потребуется, возможно дистанционное отключение воды в квартире.

\section{Список литературы}

1. Голдштейн С., Зурбалев Д., Флатов И. Оптимизация приложений на платформе .Net. М.: ДМК Пресс, 2014.

2. Lysanov D.M., Isavnin A.G., Eremina I.I., Ishmuradova I.I., Karamyshev A.N. System Design of Management of Energy Resources in the Field of Housing. HELIX. 2019. Vol. 9. Is. 4.

\section{References}

1. Goldshtejn S., Zurbalev D., Flatov I. Optimizaciya prilozhenij na platforme .Net. M.: DMK Press, 2014.

2. Lysanov D.M., Isavnin A.G., Eremina I.I., Ishmuradova I.I., Karamyshev A.N. System Design of Management of Energy Resources in the Field of Housing. HELIX. 2019. Vol. 9. Is. 4. 


\section{ДАННЫЕ ОБ АВТОРАХ}

Лысанов Денис Михайлович, кандидат технических наук, доцент

Набережночелнинский институт ФГАОУ ВО «Казанский федеральный университет»

проспект Сююмбике, 10а, г. Набережные Челны, 423812, Российская Федераиия

kampi_ldm@mail.ru

Еремина Ирина Ильинична, кандидат педагогических наук, доцент

Набережночелнинский институт ФГАОУ ВО «Казанский федеральньй университет»

проспект Сююмбике, 10а, г. Набережные Челны, 423812, Российская Федераиия

ereminaii@yandex.ru

Ишмурадова Изида Илдаровна, кандидат экономических наук, доцент

Набережночелнинский институт ФГАОУ ВО «Казанский федеральный университет»

проспект Сююмбике, 10а, г. Набережные Челны, 423812, Российская Федерация IIIshmuradova@kpfu.ru

\section{DATA ABOUT THE AUTHORS}

Lysanov Denis Mihailovich, Associate Professor, Ph.D. in Technical Sciences

Naberezhnye Chelny Institute of Kazan Federal University

Syuyumbike Avenue, 10a, Naberezhnye Chelny, 423812, Russian Federation

kampi_ldm@mail.ru

ORCID: 0000-0002-0728-4435 
Eremina Irina Ilinichna, Associate Professor, Ph.D. in Education Naberezhnye Chelny Institute of Kazan Federal University Syuyumbike Avenue, 10a, Naberezhnye Chelny, 423812, Russian Federation ereminaii@yandex.ru ORCID: 0000-0003-2333-3935

Ishmuradova Izida Ildarovna, Associate Professor, Ph.D. in Economics

Naberezhnye Chelny Institute of Kazan Federal University Syuyumbike Avenue, 10a, Naberezhnye Chelny, 423812, Russian Federation IIIshmuradova@kpfu.ru ORCID: 0000-0001-6307-8292 